\title{
A SEGUNDA PESSOA - A contribuição sistemática de Fichte ${ }^{1}$
}

\author{
Günter Zöller*
}

\begin{abstract}
O texto se debruça, sistematicamente, sobre o modo como Gotlieb Fichte apresenta a segunda pessoa, tendo o cuidado de não isolar essa exposição, que, com efeito, só pode ser compreendida no contexto integral da obra. Na recomposição do rigoroso movimento de figuras como o "Eu", o "Mim", o "Tu" e o "Nós", pretende-se mostrar como o Eu deve, enfim, ser visto em Fichte, já que se trata, primariamente, de um Nós integral e não de um Nós plural, como uma reconfiguração, em roupagem social (ou protossocial), daquele Eu pré-individual absoluto em que começou a trajetória especulativa de Fichte desde o Eu até o Mim, do Eu ao Tu, do Mim ao Ti e do Ti ao Mim, e ao qual, após a viagem pelo mundo, ela deve enfim conduzir de volta.

PALAVRAS-CHAvE: Fichte. Primeira Pessoa. Segunda Pessoa. Intersubjetividade.
\end{abstract}

Não deveria surpreender que Johann Gotlieb Fichte, o notoriamente famoso filósofo do Eu, tenha sido também o primeiro filósofo do Tu, ou seja, o primeiro filósofo que dedicou uma atenção filosófica sistemática à segunda pessoa. Talvez se pudesse até descrever a parte predominante do trabalho filosófico de Fichte como uma reflexão bastante abrangente acerca das complexas relações de reciprocidade entre as perspectivas sobre nós mesmos, que encontram sua expressão linguística na distinção gramatical entre a primeira, a segunda e a terceira pessoas. Mas a correta apreciação da contribuição dada por Fichte para a nossa compreensão da segunda pessoa, bem como da sua relação com a primeira e a terceira pessoas, é prejudicada por um duplo mal-entendido bastante difundido. Por um lado, a teoria transcendental fichtiana do Eu como princípio e fundamento de

\footnotetext{
* Doutor em Filosofia. Professor da Universidade LudwigMaximilians-Universität (Munique) e da McGill University (Canadá).

Fakultät für Philosophie, Wissenschaftstheorie und Religionswissenschaft. Ludwig-Maximilians-Universität München. Geschwister-Scholl-Platz 1. Raum A 223. 80539 München.Deutschland zoeller@lmu.de

${ }^{1}$ Tradução de Fernando Costa Mattos.
}

todo saber e de todos os seus objetos - um procedimento inspirado na filosofia transcendental de Kant e posto sob o título programático de uma "doutrina da ciência”" -é sempre compreendida equivocadamente como uma teorização psicológica sobre o significado cosmológico do Eu individual. Por outro lado, a teoria fichtiana transcendental do Tu como contrapartida originária ao Eu é reduzida a uma ontologia social que parte, sem mais, da cooriginariedade do Eu e do Tu e do efeito recíproco paritário que um tem sobre o outro.

Essa apreciação duplamente equivocada leva, de maneira típica, a desmembrar a teoria fichtiana do Eu e do Tu, radicalmente integrada, em uma teoria altamente especulativa do Eu absoluto, que se põe a si mesmo e, ao mesmo tempo, contrapõe todo o resto a si, e uma teoria igualmente vulgar da socialidade originária do Eu. Mas essa ${ }^{2}$ Fichte cunhou a expressão "doutrina da ciência” para a filosofia fundamental dos fundamentos e limites do saber de qualquer tipo, incluindo aquilo que é consciente nesse saber. Ele a empregava como substitutiva do tradicional termo "filosofia" ("amor pela sabedoria"), por oposição ao qual o neologismo de Fichte busca recuperar a pretensão à mediação da sabedoria e a ênfase no esforço pela mediação do saber e, em especial, da meta ou protossaber sobre as condiçóes de possibilidade do saber. Veja-se, com relação a isso, Zöller (1998, p. 11-24). 
recepção duplamente unívoca negligencia a engenhosa conexão estabelecida por Fichte entre o primado do Eu sobre tudo e todos e o primado concorrente, complementar e em nada contraditório, do Tu sobre o Eu. Um exame mais acurado do tratamento originariamente conexo dado por Fichte ao Eu e ao Tu pode mostrar que sua teoria do Eu é menos egoística (no sentido teórico, não moral, desse termo) do que poderia a princípio parecer, e que a sua teoria do Tu é menos altruística (sempre no sentido teórico, não moral, do termo) do que se poderia a princípio pensar. ${ }^{3}$

As seis seções seguintes se debruçam sobre seis aspectos sistemáticos distintos do modo como Fichte trata a segunda pessoa. Elas seguem aproximadamente a mesma ordem em que o próprio Fichte abordou o tema no desenvolvimento de seu sistema filosófico em Jena - desde suas partes fundantes até as partes aplicadas e as introduções propedêuticas. ${ }^{4} \mathrm{O}$ foco da apresentação analítica não se baseia, aí, num desenvolvimento filosófico qualquer de Fichte - seja na estrutura doutrinal de sua filosofia do Eu, do Tu e do Isso (Es), seja no seu modo de exposição -, mas no desdobramento arquitetônico de seu pensamento filosófico em um sistema abrangente, coerente e original. Dada a natureza altamente sistemática do pensamento de Fichte, qualquer recepção parcelada do seu tratamento de um único tema ou problema corre o risco de perder de vista a relação orgânica de cada parte singular ou aspecto de seu pensamento ao

${ }^{3}$ As ideias que serão expostas a seguir podem ser compreendidas como uma suma filosófica fundamental, historicamente articulada, da reflexão recente e recentíssima - ontológica, fenomenológica, hermenêutica e socialcrítica - sobre reconhecimento e alteridade. Cf. Theunissen, (1965; Ricoeur, (2006); Waldenfels, (2006); Honneth $(2003,2005)$.

${ }^{4}$ No que segue se fará referência sobretudo às seguintes publicações e lições de Fichte dos anos 1794 a 1799, indicandose-as em notas com as siglas entre parênteses: "Rezension des Aenesidemus" (Resenha do Aenesidemus) (Rez. Aenes.), Grundlage der gesammten Wissenschaftslehre (Fundamentos da Doutrina da Ciência completa) (GWL), Grundriss des Eigenthümlichen der Wissenschaftslehre (Esboço do caráter distintivo da Doutrina da Ciência) (GEWL), Neue Darstellung der Wissenschaftslehre, Zweite Einteilung (Nova exposição da Doutrina da Ciência, segunda introdução) (NDWL, 2. Einl.), Wissenschaftslehre nova methodo (Hallesche Nachschrift) (Doutrina da Ciência nova methodo (Posfácio de Halle)) (WLnmH) Grundlage des Naturrechts (Fundamentos do direito natural) (GNR), Das System der Sittenlehre (O sistema da Doutrina dos Costumes) (SdS). todo sistemático e, principalmente, deixar de perceber a dependência funcional de cada parte do sistema fichtiano em relação ao seu todo. A natureza sistemática do pensamento de Fichte implica, portanto, que a análise e a explicação de sua contribuição sistemática para a compreensão filosófica da segunda pessoa tenham de afastar-se do contexto temático imediato de uma filosofia social do eu (Selbst) próprio e alheio, de modo a seguir Fichte naquelas "trilhas espinhosas da crítica” que já Kant havia percorrido, ${ }^{5}$ e que o seu mais autêntico seguidor, Fichte, trata agora de seguir desbravando.

\section{O EU COMO TERCEIRA PESSOA}

A natureza complexa, multifacetada e altamente especulativa da relação entre o Eu e o Tu em Fichte se mostra já na dificuldade, por ela apresentada, para correlacionar os pronomes pessoais nominativos "Eu" e "Tu", com a diferença linguística entre as três pessoas gramaticais. Tal como já o mostra a opção por empregar o artigo definido, o uso específico das expressões "Eu" e “Tu” em Fichte não é pronominal, mas nominal, e envolve a terceira pessoa gramatical. Além disso, as expressões “o Eu” e “o Tu” aparecem quase sempre no singular.

No caso do "eu", o uso nominal do termo por Fichte dá expressão ao estatuto especial do Eu como princípio primeiro e absoluto de qualquer tipo de saber. À primeira vista, poderia parecer que o Eu fichtiano - ou, mais precisamente, aquilo a que ele chama "o Eu absoluto"6 - é uma figura que vem substituir as concepções filosóficas anteriores de um fundamento ou princípio absoluto a que tudo se subordina - como o archai dos filósofos naturais pré-socráticos, o Deus dos teólogos filosóficos medievais, ou o "Deus sive natura” de Espinosa. Expresso categorialmente, o Eu absoluto deveria ser visto, então, ou como a única substância em relação à qual todo o resto é acidente e nela inerente, ou como a causa primeira absoluta,

${ }^{5}$ Kritik der reinen Vernunft (Crítica da razão pura), B XLIII.

${ }^{6}$ GA I, 2, 271 (GWL). 
da qual todo o resto é consequência e efeito.

Mas Fichte evita usar esses títulos ontológicos tradicionais, ou, antes, se esforça para, em vista do estatuto singular do Eu absoluto, modificar significativamente tais designações. Fichte sublinha, sobretudo, que o Eu, como Eu absoluto, não é uma entidade, objetiva ou super-objetiva, que fosse numericamente diversa de nós; ele é, antes, aquilo que, em nós, constitui a estrutura fundamental de nossa existência como seres práticos, inteligentes. Além disso, segundo Fichte, o fundamento absoluto de nós mesmos tem de ser pensado como ativo e processual - não como estático e fixo - e, ainda, como autoativo ou espontaneamente ativo. Finalmente, a atividade do Eu absoluto tem de ser pensada, sempre, segundo Fichte, como originariamente autorreferente, e apenas indireta e posteriormente referida a algo diverso de si próprio. As características atribuíveis ao fundamento ou princípio absoluto levam Fichte a propor uma identificação genérica desse fundamento ou princípio com aquele complexo estrutural em nós, que é aquilo que pensa quando nós pensamos, aquilo que quer quando nós queremos, ou - falando em termos gerais - o sujeito envolvido em todas essas atividades espirituais como seu fundamento.

Mas a equiparação fichtiana do Eu absoluto com o Eu (Selbst) enquanto suporte de todas as minhas atividades espirituais é tão somente uma identificação genérica. Permanecem diferenças específicas entre o Eu absoluto e o eu comum. Primeiramente, o Eu absoluto, à diferença do eu comum, não é um eu particular, mas um Eu no sentido genérico de uma estrutura ou conjunto de condições em relação a um eu particular. Acima de tudo, porém, o Eu absoluto, à diferença do eu comum, não é caracterizado por uma consciência - nem por uma consciência reflexiva ou autoconsciência, nem por uma consciência de objetos. Por outro lado, toda e qualquer característica que seja própria ao eu comum tem de fazer parte do Eu absoluto. Do contrário, não haveria nenhuma razão ou justificativa para denominar o princípio absoluto um "Eu". No Eu absoluto tem de haver, portanto, ao menos um resto, um sinal ou um equivalente daquela autoconsciência que caracteriza o eu comum.

Aqui entra em cena a típica terminologia de Fichte, com os conceitos de "por" (Setzen) e "contrapor" (Entgegensetzen), bem como os termos e conceitos associados, em especial "sujeito-objeto", "estado-de-ação" (Thathandlung) ${ }^{9} \mathrm{e}$ "intuição intelectual" ${ }^{10}$ Todas essas expressões e peculiaridades conceituais servem para identificar e caracterizar, na constituição do eu comum, uma dimensão de caráter fundante, até então oculta, que é, ao mesmo tempo, similar e dissimilar à sua manifestação superficial - suficientemente similar para ser designada pela mesma expressão ("eu”), mas suficientemente dissimilar para que sejam afastados do Eu absoluto elementos-chave do eu comum, entre eles-em primeiro lugar-a personalidade e a manifesta autoconsciência. No que diz respeito, portanto, à atividade autorreferente que caracteriza o Eu absoluto, ${ }^{11}$ o seu por-se-a-si-mesmo incondicionado, não se trata de uma autoconsciência explicitada, mas, sim, do antecessor transcendental (o fundamento de possibilidade) desse fenômeno. De maneira perfeitamente análoga, não se deve ver a também incondicionada atividade não autorrefente do Eu absoluto - o contrapor-se do Não-Eu ${ }^{12}$ - como um caso de consciência de objetos em sentido próprio, mas sim como o seu antecessor transcendental, a sua condição específica de possibilidade.

A mesma manobra filosófica - uma denominatio principii a principiato, como se poderia denominar essa figura do pensamento - inspira a caracterização do Eu absoluto como "sujeito-objeto", uma escolha conceitual que revela a anterioridade do Eu absoluto mesmo em relação a cada diferenciação em sujeito e objeto, que ele, no 7 GA I, 2, 261 Anm. (GWL).

${ }^{8}$ GA I, 2, 255 (GWL). Sobre o conceito de Thathandlung, que Fichte introduz por oposição a Thatsache, e sua préhistória, cf. Franks (1997, p.210-323).

${ }^{9}$ Optamos por manter a tradução de Torres Filho, já consagrada entre nós, de Thathandlung por "estado-deaçã̃o". (N. T.)

${ }^{10}$ GA I, 2, 48 (Rez. Aenes.); GA I, 4, p. 216 e ss. (VNDWL, 2, Einl.), GA IV, 2, 31, 37 e ss. (WLnmHalle). Sobre a doutrina fichtiana da intuição intelectual, cf. Stolzenberg (1986)

${ }^{11}$ Cf. GA I, 2, 255 e ss. (GWL).

${ }^{12}$ Cf. GA I, 2, 246 e ss. (GWL). 
entanto, antecipa e fundamenta em uma unidade originária que, por seu turno, é pré ou protodiferenciada - ou, antes, deve ser assim pensada. Fichte segue a mesma estratégia quando caracteriza o Eu absoluto como "estado-de-ação". A precedência do Eu absoluto não é um fato (Tatsache), já que não é objeto de uma experiência possível. E, no entanto, a natureza absoluta do Eu, como fundamento incondicionado de todo fundado - um fundamento que não pode ser ele próprio fundamentado -, implica uma falta unilateral de fundamento que o aproxima da precedência contingente de um mero fato (Tatsache). Por fim, também a classificação fichtiana da atividade autorreferente e autofundante do Eu absoluto como um caso de "intuição intelectual" aponta para uma afinidade entre a consciência comum imediata de nós mesmos e a consciência de outras coisas através da intuição (sensível), sublinhando, ao mesmo tempo, contudo - tal como nos mostra o adjetivo "intelectual"-, que a imediatidade na autorreferência do Eu absoluto não está na consciência de algo particular e, portanto, não é de natureza empírica.

O procedimento que Fichte em geral adota, de caracterizar o Eu absoluto prolepticamente, por meio de termos e conceitos que surgiram no mundo fenomênico - o qual, por seu turno, só se funda no e através do Eu absoluto -, também aparece na escolha da palavra "eu" para designar o fundamento absoluto. Gramaticalmente falando, o eu do Eu absoluto não é um pronome, mas um substantivo regido pela terceira pessoa. Mas, na semântica do conceito técnico filosófico, "o eu" remete a uma relação mais interna e mais estreita entre o fundamento absoluto e nós mesmos, tal como se pode perceber também na compreensão que Fichte supõe em seus ouvintes e leitores em expressões como "mas isto sou eu mesmo" ("das bin doch ich selbst") ou "isto tem a ver comigo" ("das handelt von mir"), quando fica claro que a sua teoria transcendental do saber não diz respeito a uma terceira entidade neutra, mas a algo que constitui a nossa identidade de espécie como seres prático-racionais. Essa afinidade (afastada, como sempre) entre nós e o fundamento ou princípio absoluto de todo saber - sua identidade genérica - é a principal razão para que Fichte recorra, em tal contexto, ao termo tão técnico quanto complexo do "eu", que, ao mesmo tempo, evoca e rechaça a primeira pessoa gramatical.

Tanto do ponto de vista histórico como do sistemático, o caminho para a substantivação e a decorrente maiusculização do Eu em Fichte, ${ }^{13}$ juntamente com a despersonalização daí resultante, foi preparado através da doutrina kantiana do "eu penso" como veículo da unidade transcendental da apercepção. ${ }^{14}$ Em Kant, porém, a substantivação gramatical do $\mathrm{Eu}$ (e sua maiusculização) não se refere primariamente ao "eu", mas a toda a expressão "eu penso" - a qual, por seu turno, tem de ser ainda completada por aquilo que deve ser pensado (como, por exemplo, na frase completa "eu penso a substância"). Acresça-se a isso o fato de que Kant emprega ou descreve a construção padrão "eu penso..." de diferentes maneiras: como "juízo" (Urteil) e como "proposição" (Satz), ${ }^{15}$ e mesmo como "proposição empírica" que abarca uma "intuição empírica indeterminada" e um "sentimento". ${ }^{16} \mathrm{~A}$ expressão isolada "eu penso", ao contrário, é comparativamente rara em Kant - e isso por razões tanto textuais como doutrinais. Em uma passagem, Kant parece esforçar-se para conectar, no eu pronominal, os estatutos da terceira e da primeira pessoa, já que, de maneira gramaticalmente ousada, refere-se a "o Eu que eu penso" (das Ich, der ich denke $)^{1718}$

Uma ambivalência similar, quanto ao estatuto gramatical do Eu na expressão "eu penso",

${ }^{13}$ Em alemão, os substantivos são sempre grafados com maiúscula na primeira letra. Daí a maiusculização ser decorrente da substantivação. (N. T.)

${ }^{14}$ Cf. Kritik der reinen Vernunft (Crítica da razão pura), B, 131 e ss.

${ }^{15}$ Kritik der reinen Vernunft (Crítica da razão pura), B 399/A 341.

${ }^{16}$ Kritik der reinen Vernunft (Crítica da razão pura), B 422 e ss.; AA 4:335 Anm. (Prolegomena zu einer jeden künftigen Metaphysik (Prolegômenos a toda metafísica futura), § 48).

${ }^{17}$ Kritik der reinen Vernunft (Crítica da razão pura), B 155.

${ }^{18}$ O "certo" seria "das Ich, das ich denke", pois o "Ich", substantivado, é neutro. No entanto, Kant usou o "der" para, aparentemente, referir-se ao mesmo objeto - caso em que, por sinal, ele deveria vir declinado ("den”). Quanto a como interpretar esse "deslize”, o próprio Zöller entrará em seguida na questão. (N.T.). 
manifesta-se na caracterização experimental e disjuntiva do Eu-penso por meio da locução "este $\mathrm{Eu}$, ou Ele, ou Isto (a coisa) que pensa" (dieses Ich, oder Er, oder Es (das Ding), welches denkt). ${ }^{19} \mathrm{O}$ plano inclinado em que o sujeito transcendental parece deslizar do Eu para o Ele, e deste para o Isto, foi assim descrito ao próprio Kant pelo seu contemporâneo - e um de seus primeiros críticos -G. Chr. Lichtenberg, que propôs substituir o "eu penso" kantiano pela partícula neutra "isso pensa" (es denkt), estabelecendo uma analogia tanto gramatical quanto semântica com a expressão es blitzt ("relampeja") e buscando, assim, afastar toda e qualquer referência a uma pessoa agente. ${ }^{20} \mathrm{Na}$ perspectiva de Fichte, essa despersonalização e neutralização do sujeito transcendental ignora ou suprime a circunstância de que o princípio absoluto do saber não é um Isso (Es) com sentido de coisa, mas um Eu, ou mesmo um Além-do-Eu (Über-Ich) - como se poderia também chamá-lo, de modo a expressar o caráter supraindividual da subjetividade absoluta.

\section{O TU COMO TERCEIRA PESSOA}

Mas, em Fichte, não é só o pronome pessoal da primeira pessoa (eu) que passa por uma substantivação e uma transição para o estatuto gramatical da terceira pessoa. Também o pronome da segunda pessoa (tu) é submetido a uma substantivação, maiusculização e transição para as funções gramaticais da terceira pessoa. Mas, em geral, Fichte se mantém na semântica da segunda pessoa, de tal modo, que usos nominais como "o Tu”, "um Tu”, ou simplesmente "Tu”, referem-se exclusivamente a outras pessoas, ou então a seres que, em aspectos relevantes, são do tipo que se refere a si mesmo com a primeira pessoa gramatical.

Mas há uma exceção digna de nota quanto a essa conexão entre a terceira pessoa gramatical e a

${ }^{19}$ Kritik der reinen Vernunft (Crítica da razão pura), B 404/ A 346. Quanto a isso, cf. Sellars, W. "(...) este Eu ou ele ou isto (a coisa) que pensa (...)”. (1970-1971, p.5-31).

${ }^{20}$ Cf. Lichtenberg (1967-1974); Cf. também: Zöller (1992). segunda pessoa semântica no emprego que Fichte faz da expressão "Tu". Ela se encontra na primeira exposição - a única publicada por Fichte - de sua prima philosophia, os Fundamentos da Doutrina da Ciência completa, de 1794/5. Em uma passagem dessa obra, Fichte remete à contraposição de "Eu" e "Tu”, e o faz em um contexto que impossibilita uma referência específica a um outro eu (Selbst) - ou uma diversidade de "eus" -, apontando antes, no significado pretendido nesse uso único do "Tu”, para uma referência genérica a todo outro que não o eu. Nessa enigmática passagem, Fichte opera com uma definição minimalista e funcional do Eu e de sua contrapartida formal, o Não$\mathrm{Eu}$, segundo a qual o Eu é o "oposto" do Não-Eu e, inversamente, o Não-Eu é o oposto do Eu. Além disso, Fichte defende explicitamente, nessa mesma passagem, a reciprocidade de Eu e Não-Eu. Ele o faz com o argumento de que o Eu só é o que ele é na contraposição ao Não-Eu, e que, inversamente, o Não-Eu só pode ser o que é por oposição ao Eu.

O pano de fundo sistemático da relação igualmente oposicional e igualitária entre Eu e NãoEu, aqui defendida por Fichte, é a compreensão do Não-Eu como mero resultado do próprio contrapor-se do Não-Eu por meio do Eu e, em conexão com isso, da autodegradação do Eu, que vai do Eu como ponente universal absoluto (tanto de si mesmo como de todo o resto) para o Eu como contraposto ao Não-Eu (por meio de si mesmo). Para, contudo, dar sentido e expressão à paridade aí introduzida, e à dependência recíproca do Eu e do Não-Eu, vale-se Fichte do enunciado: "Nenhum $\mathrm{Tu}$, nenhum Eu; nenhum Eu, nenhum Tu”. ${ }^{21}$

É provável que a substituição da expressão "Não-Eu” pela expressão “Tu”, somente encontrável nessa única passagem, tenha sido motivada pela estreita conexão entre o uso da segunda pessoa gramatical (e sua forma nominal) e a relação universal de paridade e reciprocidade, na relação especificamente social, entre o eu pessoal e o tu pessoal. Mas, no caso presente, a paridade e a reciprocidade de Eu e Tu não contém os elementos de ${ }^{21}$ GA II, 2, 337 (GWL). 
personalidade da contraposição caracterizada com "Eu" e "Tu", representando, antes, uma anomalia na maneira filosoficamente refletida com que Fichte emprega a primeira e a segunda pessoa.

A proximidade gramatical e semântica com o uso comum da segunda pessoa, ou com o próprio uso filosoficamente refletido que Fichte faz da segunda pessoa substantivada em outros contextos sistemáticos e em outras de suas obras, não envolve, portanto, qualquer compreensão estreita ou personalística do Tu, na medida em que este é contraposto ao Eu na passagem mencionada. A identidade completa do Tu e do Não-Eu e a total ausência de um caráter especificamente pessoal no uso que Fichte faz do "Tu” nessa passagem são confirmadas pela manobra terminológica decisiva em que o Eu que se contrapõe ao Tu, enquanto o Não-Eu recebe a designação de "sujeito”, e o NãoEu correlativo, ou "Tu”, recebe a de "objeto". Fichte indica explicitamente, nesse contexto, que a equiparação do Eu com o sujeito e do Não-Eu com o objeto só vale na medida em que o Eu e o Não-Eu sejam correlativos - ou, antes, sejam assim considerados. ${ }^{22}$ Ela não vale para o uso não paritário e não correlativo das expressões "Eu" e "Não-Eu". Nesse último sentido não paritário, nesse modo de usar as duas expressões, nem o Eu nem o NãoEu sofrem qualquer "mudança” na relação que mantêm entre si. A "mudança” que Fichte considera válida, entre o Eu como sujeito e o Não-Eu como objeto, consiste na relação de limitação recíproca com base na qual um é o que o outro não é, e o outro é o que o um não é.

A diferenciação fichtiana entre, de um lado, o Eu correlacional e o Não-Eu correlacional (ou o sentido correlacional de Eu e Não-Eu), e, de outro, o Eu e o Não-Eu absolutos e extrarrelacionais (ou o sentido não relacional, absoluto de Eu e Não$\mathrm{Eu}$ ), oferece ainda uma razão adicional para a sua estranha escolha da expressão “Tu” para indicar a função do Não-Eu como correlato do Eu. A exemplo do termo “objeto”, a expressão “Tu” tem uma semântica relacional implícita; e, ao contrário da

${ }^{22}$ Cf. GA I, 2, 355 e ss. (GWL) semântica indicada pelos marcadores "sujeito" e "objeto", que estabelece uma dependência unilateral e univocamente direcionada, a terminologia do "Eu" e do "Tu" conota uma paridade na relação entre o Eu sujeito e o Não-Eu objeto. Também se deve notar que a equiparação de Não-Eu e Tu, no contexto específico mencionado, implica a distinção entre o sentido genérico, em que o Tu nada mais é senão o Não-Eu do Eu, e o sentido específico, em que um Tu de tipo especial - a saber, uma outra pessoa ou outras pessoas - coincide não apenas com o Não-Eu, mas também e sobretudo com o Eu.

Nessa complexa situação de um duplo Tu (um Tu genérico como Não-Eu e um Tu específico como Não-Eu-cum-Eu), não admira que alguns leitores de Fichte, apressados e voluntariosos, tenham tentado usar o lapax legomenon fichtiano - do Eu que não pode ser sem o Tu e do Tu que não pode ser sem o Eu - como evidência de uma radical interpessoalidade ou socialidade do Eu em Fichte. ${ }^{23}$ Mas ainda há um longo caminho a percorrer nessas "trilhas espinhosas" da elaboração sistemática fichtiana, desde o Eu e sua contrapartida genérica, o Não-Eu, até o Tu como o outro Eu e a concomitante superação da prioridade do Eu na relação entre o Eu e o Tu.

\section{DO EU AO MIM (VOM ICH ZU MIR)}

O primeiro grande passo em direção a um Tu específico - um Tu que não é o outro do Eu, mas um outro Eu - não conduz ainda, de modo algum, a um Tu social e intersubjetivo, mas, antes, constitui o caminho do Eu como forma supraindividual e genérica da subjetividade ao Eu como um sujeito possivelmente autoconsciente. Somente depois disso é que se abre a perspectiva mais ampla de uma multiplicidade de tais sujeitos e das possíveis relações entre eles. Nesse ponto, a exigência fundamental para cada determinação

${ }^{23}$ Cf. Philonenko (1966). Em Jacobi, podemos encontrar um exemplo de um uso contemporâneo a Fichte do "Tu" em vez do "isto" (es). Cf. Jacobi (1812-1815, Bd II, 1, p. 211). Cf. também, quanto a isso, Zöller (1998) 
posterior do Eu, bem como do Não-Eu, é a ampliação da atividade do Eu em termos de uma forma adicional do por-se.

Primeiramente, segundo Fichte, é preciso partir dos três princípios primeiros da Doutrina da Ciência, que correspondem aos três tipos de atividade do Eu absoluto ou do por-se incondicional. Trata-se da posição incondicionada do Eu absoluto por si mesmo, da posição incondicionada do Não-Eu pelo Eu absoluto e da posição incondicionada do Eu e do Não-Eu reciprocamente limitadores pelo Eu absoluto. ${ }^{24} \mathrm{O}$ primeiro ato de posição contém a atividade autorreferente do $\mathrm{Eu}$, o segundo envolve a autodiferenciação do Eu em relação a todo outro, e o terceiro inclui a dupla referência formal da exclusão e dependência recíprocas do Eu e do Não-Eu. Os termos de Fichte para os atos absolutos que estão na base das três atividades absolutas são: "tese", "antítese" e "síntese". As correspondentes formas fundamentais do juízo (ou, mais precisamente, do julgar) são aquelas dos "juízos téticos", "juízos antitéticos" e "juízos sintéticos" ${ }^{25}$ Como conteúdos estruturais básicos dos atos absolutos do Eu, essas formas não dispõem de qualquer conteúdo específico ou determinado, mas são, antes, os meros tipos e modos fundamentais pelos quais qualquer tipo de conteúdo é formado ou construído pelo Eu.

As atividades básicas incondicionadas do Eu absoluto, quer sejam téticas, antitéticas ou sintéticas, apontam para uma estrutura autorreferente, ou um voltar-se sobre si mesmo do Eu - uma direta autorreferencialidade no caso da autoposição incondicionada do Eu por si mesmo, e uma autorreferencialidade indireta tanto no caso da contraposição do Não-Eu, que é um contrapor-se a si mesmo do Eu absoluto, como naquele da posição divisível do Eu e do Não-Eu, em que o Eu absoluto se autotransfere à divisibilidade. Mas, em nenhum desses casos de autorreferência, é posta a autorreferencialidade do Eu enquanto tal. O absoluto por-se-a-si-mesmo do Eu é, portanto, uma

${ }^{24}$ Cf. GA I, 2, 255 e ss., 264 e ss. e 267 e ss. (GWL).

${ }^{25} \mathrm{GA} \mathrm{I}, 2$, 274 e 276 (GWL). autorrelação que, enquanto tal, só é observável por um observador externo (ou, mais precisamente, aquele que faz o experimento do Eu). ${ }^{26} \mathrm{Tem}$ de haver um ato adicional de atenção por parte do $\mathrm{Eu}$, metodicamente controlado, para ele por-se como ponente..$^{27}$ Nesse caso, segundo Fichte, o ato da atividade autorreferente reflexivamente duplicante - de uma segunda atividade autorreferente que se remete à primeira - não é um ato incondicionado, como o eram os três atos básicos de posição antes distinguidos, mas um ato condicionado - e, nessa medida, contingente -, cuja ocorrência depende de outras circunstâncias. Entre essas circunstâncias adicionalmente exigidas está o contato protossocial do Eu, ainda por esclarecer.

Pensando nos termos conceituais da divisão tripartite das atividades ponentes do Eu, a progressão sistemática - que vai da simples e irrefletida autoposição do Eu à sua possível autoposiçãode-si reflexiva dúplice como autoposição-de-si exige uma síntese própria. Diferentemente, porém, do ato sintético incondicionado acima introduzido, da posição (da divisibilidade) do Eu e do NãoEu na relação de exclusão e dependência recíprocas entre eles, a síntese originária (mas condicionada) exigida para o surgimento de um Eu que, para ser possível, deve dispor de efetiva autoconsciência, não contém a contraposição de um Não-Eu ao Eu que se pôs a si mesmo. A síntese da autoconsciência é, antes, uma "síntese do Eu consigo mesmo”, com exclusão do Não-Eu. Em conexão com isso, Fichte acrescenta o seguinte: "o ponente que, no ato descrito, põe-se a si mesmo não como ponente em geral, mas como ponente do Eu, sou eu..." ${ }^{28}$ Com essa identificação especificante, é dado o passo do Eu ao mim, ou ao Eu-para-mim.

${ }^{26}$ Sobre a reconstrução experimental fichtiana do Eu absoluto, cf. Zöller, G. An eye for an I: fichte's transcendental experiment. In: Klemm; Zöller (1997, p. 73-95).

${ }^{27}$ GA I, 2, 406, 409 (GWL). Sobre a passagem fichtiana da autoposição do Eu à sua autoposição-de-si-mesmo como ponente de si mesmo, cf. Zöller (1998a, p. 43-54).

${ }^{28}$ GA, I, 4, 255 (VNDWL, 2, Einl.) 


\section{DOEUAOTU}

OEu reflexivo, sintetizado consigo mesmo, já não é o mero núcleo pré-pessoal do Eu ou o Eu nuclear ("Eu absoluto") do começo da "História pragmática do espírito humano" narrada por Fichte. ${ }^{29}$ Mas também não se trata, ainda, no Eu heautossintetizado, do ponto final visado por essa história (ou narração da história), a autoconsciência de conteúdo específico plenamente desenvolvida. Para atingir o último estágio, têm de ser satisfeitas outras pressuposições fundamentais. Até aqui, o que temos é somente um Eu que está estruturalmente preparado para o possível surgimento da autoconsciência. Há duas condições fundamentais, em particular, que têm de ser preenchidas para o surgimento da autoconsciência plenamente desenvolvida: o Eu tem de ser individuado, e o Eu individuado tem de ser trazido à consciência de sua própria existência e de seu modo de ser e, ao mesmo tempo, a agir em consonância com essa sua natureza essencial. Segundo Fichte, a exigência da individuação do Eu é satisfeita com a autoatribuição de um corpo pertencente exclusivamente a ele (de "carne e osso"), ${ }^{30}$ ao passo que o despertar transcendental do Eu envolve um outro Eu, já desenvolvido (desperto). ${ }^{31}$

Além disso, ambas as exigências fundamentais suplementares não devem ser vistas como sucessivamente preenchíveis ou por preencher. A exemplo da história de formação do Eu, diacronicamente representada, também os passos que vêm completar a constituição elementar do Eu não são fases distintas, mas muitos momentos de um processo interativo complexo da autoconstituição, que só aparece como temporalmente dilatado na reconstrução artificial do filósofo. Segundo Fichte, a efe-

${ }^{29}$ Cf. GA I, 2, 365. Sobre a natureza da Doutrina da Ciência como um devir do espírito narrado reconstrutivamente, cf. Claesges (1974).

${ }^{30} \mathrm{Na}$ verdade, Zöller usou as duas palavras alemãs que correspondem a "corpo": Körper na primeira ocorrência (que traduzimos por "corpo") e Leib entre parênteses e entre aspas, como que se referindo ao aspecto empírico do corpo - daí a termos traduzido por "de carne e osso". (N. T.)

${ }^{31}$ Cf. GA I, 3, 361 e ss. (GNR) Cf. também Zöller (2011, p.97-111); Zöller, (2006, p. 90-106). tiva consolidação do Eu acontece instantaneamente, ou "num só golpe”, como Fichte, recorrendo à arte de confeccionar moedas, denomina metaforicamente esse acontecimento. As moedas não são criadas cunhando-se primeiro o lado da frente e depois o lado de trás. A moeda é criada - e com ela os seus lados - de uma só vez, através de um único carimbo da máquina.

Antes, porém, que se possa chegar às duas determinações seguintes do Eu, conectadas entre si, através do próprio corpo e de um outro Eu, tem de ser preparado o espaço conceitual para a entrada em cena do Tu. O próprio Fichte fala disso, dizendo que o "conceito" do Tu tem de ser desenvolvido primeiro. ${ }^{32}$ Esse passo preparatório não contém ainda uma relação recíproca entre o Eu e o Tu, mas apenas uma posição inicial e mínima do Não-Eu como Tu. O procedimento é análogo ao por originário do Eu como mim, acima explicado. Novamente é exigida uma síntese originária, mas por isso mesmo condicionada e contingente. Dessa vez, no entanto, não é uma síntese do Eu consigo mesmo, mas uma síntese ou "unificação do Isso e do Eu". ${ }^{33} \mathrm{O}$ termo "isso", aqui introduzido por Fichte, designa a concepção genérica e indiferenciada do Não-Eu como tudo aquilo que o Eu não é. À primeira vista, pode parecer contraditório querer unir o conceito do Eu com o do Isso como Não-Eu. Afinal, os dois conceitos determinam de tal maneira um ao outro que um exclui diretamente o outro. Na concepção de uma unificação sintética do Eu e do Não-Eu, trata-se de um problema sistemático, ou o estabelecimento de uma tarefa para a progressão dedutiva na reconstrução do Eu, cuja solução está na introdução do Tu, na invenção - um descobrir no sentido de inventar (Findung wie Erfindung) - do Tu pelo Eu. A tarefa de unificar e, portanto, colocar em consonância, em um mesmo ser, as características essenciais do Eu e do Não-Eu, que se excluem reciprocamente, conduz ao conceito de um Não-Eu que, entretanto, é um Eu; e conduz também, desse modo, a um Eu

\footnotetext{
${ }^{32}$ GA I, 4, 255 (VNDWL).

${ }^{33}$ Idem, ibidem.
} 
diferente daquele que fora considerado, até aqui, na atividade tética, antitética e sintética do Eu.

Segundo a avaliação de Fichte, a síntese resultante na posição do Tu acontece juntamente com a síntese resultante no Eu enquanto mim, anteriormente descrita, que desemboca no Eu enquanto $\mathrm{Eu}$, ou no Eu-Eu, como se poderia denominá-lo. O ponente de si mesmo como Eu põe "no mesmo ato", nos termos de Fichte, o Não-Eu como Eu, ou o Tu-Eu, como se poderia denominá-lo. De qualquer modo, nessa etapa do desenvolvimento do $\mathrm{Eu}$, ou de sua reconstrução experimental, o Tu-Eu não é levado em conta como um Eu que se põe a si mesmo, mas apenas como um Eu posto através de mim. O outro Eu não é posto ainda, de sua parte, como sendo por si mesmo (für sich seiend). Quanto a isso, Fichte diz: "[...] e aquilo que é posto como Eu no mesmo ato através de mim, e não por si mesmo, és tu [...]." ${ }^{34}$

Se Fichte concede aqui que o Tu-Eu posto pelo Eu é posto como um Eu, mas recusa, ao mesmo tempo, que o Tu-Eu seja posto também como ponente de si mesmo, isto não impede que o TuEu venha a aparecer, sob um outro aspecto e em um ponto posterior da argumentação, como ponente de si mesmo e, além disso, como ponente de si mesmo enquanto ponente de si mesmo - do mesmo modo como o Eu-Eu. Contudo, nesse ponto do caminho sistemático de seu pensamento, Fichte parte apenas de que a constituição originária do Tu-Eu - o seu por-se pelo Eu - traz o Tu-Eu à luz, primeiramente, sob a perspectiva do Eu-Eu. $\mathrm{Na}$ apreciação de Fichte, o Tu-Eu é originariamente um "isso enquanto mero objeto" ao qual o conceito do Eu foi "transferido" (übertragen).$^{35}$ No entanto, Fichte também considera válida, desde o começo, a identidade estrutural genérica do Eu$\mathrm{Eu}$ e do Tu-Eu, ao colocar as duas formas do Eu sob o conceito de espécie do "Eu em geral" e definir esse último, negativamente, como Não-objeto" . ${ }^{36}$

\footnotetext{
${ }^{34}$ Idem, ibidem.

${ }^{35}$ Idem, ibidem.

${ }^{36}$ Idem, ibidem.
}

\section{DO TI AO MIM E DO MIM AO TI (VOM DIR ZU MIR UND VON MIR ZU DIR)}

Depois de atingido o estágio conceitual da autodiferenciação do Eu no Eu-Eu, Tu-Eu e Isso, pode ser dado o passo sistemático para a apresentação de uma relação específica entre as duas formas pessoais do Eu. Tal como já antecipado, o passo seguinte, do Eu-Eu e do Tu-Eu ao Mim e ao Ti contém duas etapas diferenciáveis, ainda que ligadas uma à outra: a posição do próprio corpo (“de carne e osso") do Eu-Eu pelo Eu-Eu e a posição do Tu-Eu pelo Eu-Eu, como operando sobre o Eu-Eu.

Na mediação das especificidades do Mim e do Ti e da relação que mantêm entre si, Fichte procede mediando as condições de possibilidade da autoconsciência de conteúdo específico da parte do Eu-Eu. Segundo a análise de Fichte, o Eu-Eu só pode tornar-se consciente de si mesmo enquanto tal e em suas relações, quando, para além das já explicadas características essenciais universais, preenche também outras condições fundamentais específicas. A essas pertence, em primeiro lugar, o engajamento do Eu com o Não-Eu na forma de uma eficiência causal, ou de uma eficiência causal perseguida, que submete o Não-Eu e sua relação com o Eu à mudança. Em termos mais precisos, as especificidades do Eu-Eu e do Tu-Eu, inclusive a sua relação entre si, são aí deduzidas como pressuposições estruturais necessárias do caráter fundamentalmente prático do Eu.

Mas as condições de possibilidade da autoconsciência não são cognitivamente acessíveis, sem mais, ao Eu que é constituído a partir delas. Na verdade, elas se abrem primeiramente à reconstrução filosófica artificial da gênese do Eu transcendental. Segundo Fichte, a perspectiva originariamente limitada do Eu, para quem a própria realização transcendental costuma passar despercebida, vem a si como expressão de que o Eu não tem a experiência originária de si mesmo em sua atividade fundamental de autoposição e autoposição de si (e nem poderia tê-la), mas a tem - ou se "encontra" (findet) - na experiência de si 
mesmo como já existente e dado de outro modo. ${ }^{37}$ É evidente que o Eu não se descobre, em sua experiência originária de si mesmo, como coisa, objeto ou Não-Eu, mas sempre como já dotado do caráter essencial prático-egoico da autoatividade em relação consigo mesmo. Devido à sua natureza de eu, o Eu sempre se descobre como "querente" (wollend) ${ }^{38} \mathrm{~A}$ introdução, por Fichte, da expressão "encontrar" (finden), ou, antes, "encontrar-se" (sich finden), para descrever a autodescoberta originária do Eu, não deveria ser compreendida, portanto, como se se afirmasse, com isso, que a natureza prática fundamental do Eu seria um mero fato e, portanto, que toda tentativa de esclarecê-la recorrendo a fundamentos deveria ser suspensa. A cuidadosa escolha das palavras por Fichte aponta, antes, para o modo como aquilo que tem de ser explicitado se furta à consciência “comum” emergente, pré-filosófica. Do ponto de vista filosófico, a autorrelação prática originária do Eu, juntamente com a correspondente provisão de um corpo e a correlação com uma confrontação de caráter pessoal, não é algo que esteja originariamente descoberto, mas algo cuja possibilidade de ser descoberto (Vorfindlichkeit) resulta de uma limitação da autoposição absoluta do Eu, que é anterior a qualquer possibilidade de encontrar algo (Findlichkeit), e que forma a autoconstituição clandestina do Eu. A limitação da posição do Eu é também a posição limitada do Eu.

Ao ver de Fichte, a autoexperiência originária do Eu como um Eu prático - como "querente" e, nessa medida, determinante do Não-Eu - contém, antes de mais nada, a trans-posição (VerSetzung) do Eu para uma relação efetiva com objetos materiais sobre os quais ele pode agir. Fichte pressupõe aqui a passagem do Não-Eu a objetos plurais no espaço e no tempo e sua ordenação segundo leis. ${ }^{39} \mathrm{Em}$ particular, o Eu é forçado a porse a si mesmo como conectado com um e apenas um objeto encontrável (ou, mais precisamente, criável) dentre os muitos objetos materiais do

${ }^{37}$ Cf. GA I, 3, 343 (GNR) e GA I, 5, 37 (SdS).

${ }^{38} \mathrm{Cf}$. GA I, 5, 37 e ss.

${ }^{39}$ GA I, 3, 200 e ss. (GEWL) mundo. Esse específico objeto espaço-temporal diferencia-se de todos os objetos possíveis por estar sob o controle exclusivo e imediato do Eu-Eu. Cada querer do Eu-Eu conduz imediatamente a uma modificação no objeto material com que o EuEu se relaciona interna e exclusivamente. O objeto em questão é o "corpo" (Leib) do Eu-Eu, compreendido como o veículo para a sua presença ativa e volitivamente determinada no mundo dos objetos. ${ }^{40}$ Todos os demais objetos submetidos às ocupações práticas do Eu no mundo só se subordinam à atividade prática do Eu-Eu mediatamente e, no fim das contas, são mediados através da atividade imediata anterior do Eu-Eu em seu próprio corpo.

Antes, porém, que o Eu-Eu corporificado possa ser visto como estruturalmente preparado para a contraposição prática com o mundo, há ainda um importante problema a resolver. Pois, para poder passar do querer como faculdade para um querer efetivo, é necessário que o Eu-Eu queira ou possa querer - algo determinado, uma meta de conteúdo específico ou um "fim" (Zweck) que se efetive - ou possa efetivar-se - através do movimento corpóreo conectado exclusivamente ao EuEu e o efeito dele resultante sobre o mundo dos objetos. Essa exigência de uma determinação finalística do querer exige, contudo, por seu turno, um conhecimento do mundo dos objetos com o qual o Eu-Eu esteja em condições de escolher, dentre os objetos ou suas partes e aspectos, aquele que possa ser efetivamente modificado pelo querer do Eu-Eu e a sua manifestação corpórea concomitante. Inversamente, porém, também não pode haver, segundo Fichte, um acesso ao mundo por parte do Eu-Eu que precedesse a sua intenção prática atinente à vontade: o que aparece primeiramente, a partir da autorrelação prática originária do Eu, é o próprio Eu, e com ele o mundo dos objetos que lhe é correlativo. De acordo com Fichte, qualquer acesso cognitivo e fortemente teórico ao mundo e seus objetos sempre pressupõe, antes, a sua abertura prática através da atividade da vontade.É somente sobre a base do acesso prático origi-

${ }^{40}$ Cf. GA I, 3, 361 e ss. (GNR) 
nário ao mundo dos objetos e aos objetos do mundo que o Eu-Eu pode fazer abstração da modalidade prática de sua relação ao mundo e aos objetos, volitiva e centrada em fins, para realizar aquela mudança de perspectiva pela qual vem à luz o objeto como tal, independentemente da determinação pela vontade e da colocação de fins, e com foco em sua determinação teórica. ${ }^{41}$

A pressuposição recíproca do conhecimento (de objetos) para o querer (fins), e do querer (um fim) para o conhecimento (de um objeto) mantém o Eu, na avaliação de Fichte, preso em um "círculo" que, se permanecesse, significaria o declínio da funcionalidade tanto teórica como prática do Eu e, com isso, do Eu em geral - ou de sua reconstrução filosófica. ${ }^{42} \mathrm{Em}$ vez, porém, de tomar o círculo como uma objeção contra a própria teoria do Eu, Fichte integra o aparente defeito no desenvolvimento de sua construção teórica. Para tal, ele reinterpreta o círculo como anúncio do estabelecimento de uma tarefa filosófica: trabalhar essa determinação do Eu, igualmente presente no conhecer e no querer, de tal modo que o Eu escape, através do recurso a um fundamento pré-disjuntivo do conhecer e do querer, a essa relação recíproca, circular e problemática entre eles. Ora, a solução do problema do círculo e da passagem a um Eu capaz de, em princípio, desempenhar diversas funções, consiste, em Fichte, em que o Eu que se percebe como querente descobre em si, ao mesmo tempo, com essa determinação fundamental, uma outra síntese (formulando filosoficamente: põe-se a si mesmo como assim sintetizante) em que as metades do círculo, de outro modo distintas (o conhecimento de um objeto e o querer de um fim), são originariamente unidas. A solução consiste na unidade - originariamente sintética e anterior a qualquer análise - do objeto do conhecimento e do fim da vontade. Olhando mais de perto, a uni-

\footnotetext{
${ }^{41} \mathrm{O}$ primado sistemático da posição prática e volitiva em relação ao mundo, comparada à posição teórica e cognitiva - e, com isso, o primado do prático em relação ao teórico -, é um aspecto crucial da teoria central de Fichte sobre “o primado da razão prática”. Com relação a isso, cf. Breazeale (2006, p.39-72).

${ }^{42}$ GA I, 3, 340-1. (GNR)
}

dade sintética buscada tem, por um lado, de ser constituída de tal modo, que o objeto do conhecimento não seja outra coisa senão a formação originária da vontade do Eu objetivada, e, por outro lado, tem de ser de tal espécie, que a formação originária da vontade do Eu não contenha qualquer fim fora do Eu que pudesse ser conhecido separadamente, mas apenas o proto-meta-fim da formação originária da vontade do próprio Eu. ${ }^{43}$

Do ponto de vista estrutural, a síntese originária exigida por Fichte, do conhecer e do querer em um protoquerer que é, ao mesmo tempo, um protoconhecer (ou um conhecer originário que é ao mesmo tempo um querer originário), é um "ser-determinado do sujeito para a autodeterminação" (Bestimmtseyn des Subjekts zur Selbstbestimmung). ${ }^{44}$ O momento aí exigível do querer reside no conhecimento completo de sua determinação descoberta (vorgefundene). Mas essa é uma determinação ou destinaçãa ${ }^{45}$ (para a autodeterminação) diferente de todas as outras determinações que o Eu encontra - ou põe - ao ocupar-se de objetos de todos os tipos. Na destinação do Eu para a autodeterminação, tão singular quanto originária, trata-se de um ser-determinado do Eu, que é absolutamente mínimo e formal e aponta unicamente para o querer autossuficiente do Eu. A síntese originária do conhecer e do querer consiste, portanto, na subordinação do Eu a uma determinação que ele tem de conhecer e cuja única função é fazer com que o Eu se determine a si mesmo. Trata-se de um protoconhecimento que deve ser, em geral, querido, e de um protoquerer do querer como tal.

Fichte dá à determinação originária própria a que o Eu se subordina, e que é fortemente limitada a induzir a autodeterminação do Eu, o nome de "solicitação" (Aufforderung) ou, mais precisamente, de "mera solicitação para que o sujeito aja". ${ }^{46}$

${ }^{43}$ Cf. GA I, 3, 342 e ss.

(GNR) e GA IV, 2, 129-30 (WLnmH).

${ }^{44}$ GA I, 3, 342 (na grafia original) (GNR).

${ }^{45}$ Nesta ocorrência, a palavra Bestimmung passa a aparecer também com o sentido de “destinação”. O próprio Zöller, algumas páginas adiante, se valerá das palavras Determination e Destination, de origem latina, para indicar essa duplicidade semântica da palavra Bestimmung. (N.T.)

${ }^{46}$ GA I, 3, 342 (GNR). 
Subordinar-se à solicitação e, assim, entendê-la como tal, tem, para o sujeito, o mesmo significado que a compreensão de que está submetido a uma limitação que só se deixa suspender, quando muito, na medida em que deixa para a autodeterminação do Eu todas as demais determinações do Eu e, portanto, todo tornar-se determinado (Bestimmtwerden) do Eu. Através do contexto de transição, estruturalmente ancorado na solicitação, que leva da determinação alheia mínima à máxima autodeterminação, o Eu se vê em condições de descobrir e ativar, a partir da incitação alheia, o próprio potencial para a atividade livre e autoinduzida.

Segundo Fichte, o entendimento pelo qual o eu assume a destinação para a autodeterminação implica que o Eu determinado não possa localizar a origem da solicitação em um objeto habitual, o qual não serviria para produzir uma determinação tão controlada e maximamente assumida. Na solicitação, assim compreendida, o Eu se percebe considerado como um ser potencialmente livre e autodeterminado, e se percebe assim considerado por um ser que ele próprio tem de considerar (ou por como) livre e autodeterminante. O solicitante por trás da solicitação tem de ser pensado pelo Eu solicitado como um ser igual a si, a não ser pela diferença de que a atividade prático-inteligente livre, que só se inicia no solicitado através da solicitação, tem de ser considerada como já manifesta e exercida no solicitante. ${ }^{47}$

Além disso, o Eu submetido à solicitação tem de se pensar como constituído de tal modo e pensar-se a si mesmo como assim constituído que está aberto para ele o modo singular de produzir efeito colocado pela solicitação. ${ }^{48}$ Embora esse modo de produzir efeito se diferencie, de fato, do mero exercício de força física, nem por isso a solicitação prescinde de um meio corpóreo para, por meio da produção de efeito no corpo do Eu solicitado, produzir efeito sobre ele próprio. Em conexão com isso, Fichte estabelece uma distinção entre o "efeito livre" (freier Einfluss) e o "efeito não livre" (unfreier Einfluss) que podem ser exercidos

${ }^{47}$ Cf. GA I, 3, 344 e ss. (GNR)

${ }^{48}$ GA I, 3, 361 e ss. sobre o Eu, e entre as funções correspondentes na receptividade corpórea do Eu ("sentido superior", "sentido inferior")..$^{49}$ Além disso, o Eu solicitado tem de ser pensado - e pensar-se - como capaz de reagir proporcionalmente à solicitação feita (e como tal compreendida), a saber, não através do mero exercício físico da força, mas de tal modo que o Eu solicitado, em contrapartida, também reconheça e trate o solicitante como um ser livre. A capacidade do Eu solicitado de responder ao efeito livre da solicitação tem por pressuposição que o Eu solicitado, graças à sua constituição corpórea, dispõe não apenas dos meios para produzir a modificação física, mas também das específicas funções e meios do efeito "livre" ("órgãos superiores"). ${ }^{50}$

Por fim, o Eu-Eu tem de ser pensado como constituído de tal modo - e tem de pensar-se a si mesmo como assim constituído - que somente o Eu solicitante pode descobrir em si o potencial para um comportamento livre e inteligente e, através da percepção desse potencial, ser levado a iniciar a solicitação. O Eu que tem de ser solicitado à ipseidade (Ichlichkeit) pode não parecer somente um Não-Eu para o Eu capaz da solicitação, mas um Não-Eu capaz da ipseidade e, além disso, destinado à ipseidade. Segundo Fichte, essa condição é satisfeita com a presença de manifestações externas e corpóreas do potencial para o agir livre e inteligente no Eu solicitante, em particular uma constituição corpórea que revele habilidades para muitos e diferentes fins - tais como aqueles que se põem e perseguem um ser que não se restringe a fins naturais, mas é capaz e determinado à livre posição de fins. ${ }^{51} \mathrm{O}$ termo de Fichte para o ato cognitivo do Eu solicitante, em que este compreende a manifesta capacidade do Eu que é tão capaz quanto necessitado da solicitação, é "reconhecimento" (Anerkennung). A expressão é uma versão abreviada do enunciado detalhado em que o ser em questão é reconhecido como ser racionalmente capaz pelo solicitante. ${ }^{52}$ No uso que Fichte faz do

${ }^{49}$ Cf. GA I, 3, 368 e ss. (GNR)

${ }^{50}$ Cf. GA I, 3, 367 e ss. (GNR)

${ }^{51}$ Cf. GA I, 3, 379 e ss. (GNR)

${ }^{52}$ Cf. GA I, 3, 351 e ss. (GNR) 
termo, porém, a expressão “reconhecimento” contém não apenas a percepção cognitiva da presença do potencial racional em outro ser, mas também o comportamento perante esse outro ser que surge junto com tal compreensão e lhe é conforme. Além disso, Fichte também emprega a expressão teórico-prática do "reconhecimento" para o comportamento decorrente do ato originário de reconhecimento (e conforme a ele), da influência recíproca, livre e continuada, entre o solicitante originário e o solicitado originário.

\section{DO MIM E DO TI AO NÓS}

Em seu sentido derivado, como conceito fundamental do reconhecimento retribuído e repetido entre o Eu e o $\mathrm{Tu}$, o termo e conceito do reconhecimento, introduzido na filosofia prática por Fichte, se tornaria um ponto de partida de grande influência para a reflexão posterior sobre a socialidade do sujeito. ${ }^{53}$

Deve-se ter presente, contudo, que o conceito fichtiano de reconhecimento não contém ainda, em sua função e significado originais, as características distintivas da reciprocidade e da equidade que ele teria em seu uso hegeliano. ${ }^{54} \mathrm{Em}$ primeiro plano, "reconhecimento" designa, em Fichte, o tratamento - fundado em uma realização cognitiva e sua correspondente intenção volitiva - do objeto da solicitação como um sujeito ou um Eu com seus próprios direitos - ou ao menos como alguém capaz e determinado para essa subjetividade prático-racional, ainda que incapaz de chegar a ela sozinho e, por isso, necessitado de uma solicitação à autodeterminação. Em Fichte, portanto, o ato originário do reconhecimento é unilateral e só ocorre uma vez. Em termos empíricos (da empiria social), trata-se, na solicitação, de uma passagem ontogeneticamente única, filogeneticamente universal - à educação para a maioridade e a capacidade de um uso independente da razão.

${ }^{53}$ Sobre isso, cf. Williams $(1992,1998)$. Para uma abordagem diferenciada, cf. Bubner (2001, p. 610-669).

${ }^{54}$ Cf. HEGEL, Akad-Ausg, 9, 109 e ss.
O passo que leva do ato originário e unilateral do reconhecimento para o reconhecimento evoluído e recíproco entre o sujeito e o objeto da solicitação originária, bem como o segundo passo rumo a uma pluralidade de inteligências livres reconhecendo-se umas às outras, dependem da satisfação de outras condições, segundo Fichte, e são acontecimentos contingentes. Para responder ao reconhecimento a ele dirigido, o Eu solicitado deve, primeiramente, observar padrões mínimos de racionalidade, em especial o princípio de agir de modo consistente com a maneira pela qual foi tratado na solicitação originária. Essa consistência não é garantida apenas por tratar-se de um ser igual a nós, que, embora capaz de agir racionalmente, não o faz necessariamente (vista a questão de um ponto de vista estático, e não modal). Um ser solicitado à autoconsciência que logra atingi-la também poderia comportar-se de maneira ingrata para com o Eu que o solicitou a isso e - qualquer que fosse a razão para isso - não retribuir o reconhecimento. ${ }^{55}$

Em vista da contingência por princípio do reconhecimento recíproco e evoluído, e do risco elementar do não reconhecimento corrido pelo solicitante, Fichte chega a dois procedimentos para assegurar a reciprocidade do reconhecimento: o direito e a moralidade. $O$ direito, que diz respeito ao contrato e conduz a uma ordem política, estabelece limitações externas ao agir dos seres racionais livres uns em relação aos outros. O reconhecimento recíproco e evoluído que é assim promovido não se funda na disposição moral, mas no medo de sanções pelo sistema jurídico penal. Mesmo a comunidade produzida pelo direito abarca apenas um número limitado de membros, tipicamente burgueses ou participantes de um corpo estatal que governa o direito. Fichte propõe inclusive que, como parte de sua pena, o criminoso seja banido da comunidade jurídica e, portanto, excluído da proteção do direito. ${ }^{56}$ No que diz respeito à relação entre o Eu e o Tu, deve-se ter presente que, em Fichte, a comunidade jurídica de reconhecimento é, essencialmente, uma comuni-

${ }^{55}$ Cf. GA I, 3, 384 e ss. (GNR)

${ }^{56}$ Cf. GA I, 3, 388 (GNR). 
dade que rege o uso não conflitivo dos pronomes pessoais da primeira e da segunda pessoa. A lei e sua base política, o Estado de direito, são, basicamente, instituições para a promoção e a manutenção do Meu e do Teu, ou da atribuição e garantia das propriedades e títulos de todos os tipos. Consequentemente, é externa a relação de reconhecimento na comunidade jurídica.

A segunda forma fundamental das relações interpessoais distinguida por Fichte, em que se chega ao reconhecimento recíproco evoluído, é a comunidade ética ou moral. Diferentemente, contudo, do que ocorre na comunidade jurídica estatal, o pertencimento à ordem moral é universal e externamente imperceptível. Segundo Fichte, todo ser inteligente livre é internamente compelido a querer o moralmente devido (Moralisch-Gesollten). A qualidade moral do agir racional livre não é um acontecimento de escolha arbitrária. Tomada em sentido forte, a autodeterminação, que o ser racional prático descobre como sua determinação (Determination) e destinação (Destination) ("Bestimmung") ${ }^{57}$ graças à solicitação, ${ }^{58}$ afasta qualquer uso arbitrário da liberdade e orienta todo agir para a norma absoluta da liberdade em nome dela própria.$^{59}$ De qualquer modo, nem o conhecimento da própria destinação moral nem a disposição de viver e agir que é correspondente a tal discernimento podem estar submetidos a uma obrigação coercitiva ou constituir o objeto de uma ameaça ou prêmio. Quaisquer meios externos para promover a moralidade estariam em contradição com a sua origem na autoconsciência livre. Consequentemente, a comunidade moral não é, para Fichte, uma realidade social como o Estado e sua ordem jurídica, mas, sim, uma "comunidade ética" invisível a que todos devem pertencer, ${ }^{60} \mathrm{e}$ à qual Fichte dá o nome - seguindo Kant nesse ponto - de "igreja", de modo a indicar a possível par-

${ }^{57}$ Cf. nota 44 , supra. (N.T.)

${ }^{58}$ Sobre o conceito teleológico da destinação em Fichte, cf. Zöller (2001, v. 4, p. 476-89).

${ }^{59} \mathrm{Cf}$. GA I, 5, 132 (SdS). Sobre a doutrina moral de Fichte como teoria das condições formais e materiais da possibilidade da liberdade moral, cf. Zöller (2005, p. 203-229). ${ }^{60}$ GA I, 5, 213 (SdS). ticipação universal e o caráter interno, baseado na intenção da união de seus membros. ${ }^{61}$

A comunidade moral, com sua extensão máxima ideal a todos os seres racionais livres, parece agora a arena perfeita para a práxis do reconhecimento recíproco. Mas um olhar mais detido sobre a visão fichtiana do mundo moral desvenda uma característica dessa ordem que se opõe diretamente a um traço fundamental do conceito de reconhecimento e, em geral, da filosofia social do reconhecimento inspirada em Fichte, a saber, o seu imperativo social de considerar e tratar o outro $E u$ como outro Eu, isto é, como não apenas igual a mim, mas também como diferente de mim e, justamente por isso, tão digno de valor quanto eu. $\mathrm{Na}$ concepção fichtiana ideal do mundo ético, ao contrário, todos têm o mesmo fim último (a liberdade em nome dela própria) e, no fim das contas, também querem todos o mesmo: "Na medida em que toda a sua individualidade desaparece e é aniquilada, cada um se torna uma pura representação da lei moral no mundo sensível; um Eu propriamente puro, através da livre escolha, e autodeterminação." ${ }^{2}$

Do ponto de vista da moralidade, a individualidade do $\mathrm{Eu}$ - tanto do próprio Eu como de todos os outros - não é senão a ferramenta ou "veículo" que entra em cena em meio ao projeto ético universal da difusão e domínio da razão. ${ }^{63}$ A meta a que servem os veículos egoicos (ichlichen) não é a liberdade do Eu individual, juntamente com seu reconhecimento universal, tampouco a liberdade da comunidade. Ela é, antes, a "razão em geral", e sua liberdade em relação a tudo o que não é razão ou racional. Essa perspectiva finalística supraindividual da filosofia transcendental de Fichte corresponde ao fato de que o foco da relação de reconhecimento na comunidade ética não é posto na relação recíproca entre o Mim e o Ti, mas na imersão

${ }^{61}$ GA I, 5, 213 e ss. (SdS) Kant. Akad-Ausg, 6, 100 e ss. (Die Religion innerhald der Grenzen der blossen Vernunft (A religiã̃o nos limites da simples razão), terceira parte.) ${ }^{62} \mathrm{GA}$ I, 5, 231 (SdS).

${ }^{63}$ Cf. GA I, 5, 198 (SdS). Veja-se também a versão fichtiana da doutrina kantiana do estabelecimento de fins para si mesmo como algo essencial ao ser humano, e que é transferida do plano individual para o supra-individualintegral ("propriamente falando, o ponto de vista de Deus") (GA I, 5, 230 [SdS]). 
da individualidade da primeira e da segunda pessoa em uma "vontade comum" indiferenciada que a tudo abarca-em um Nós, portanto. ${ }^{64}$

É particularmente importante e característica, para a dimensão especulativa da visão social ética de Fichte, a circunstância de que o Nós ideal da comunidade moral não seja o resultado decorrente da livre associação prévia dos Eus individuais (e Tus individuais) com base em sua relação de reconhecimento recíproco. No lugar de um contratualismo moral, Fichte coloca a prioridade do Nós como origem pré-individual da individualidade. O Nós deve ser considerado como uma condição prévia e uma base ("massa" [Masse]) ${ }^{65}$ para uma divisão segura entre indivíduos que são Eus e Tus na relação entre si, mas cuja destinação última é a infinita reaproximação do estado originário de sua não-distinção. ${ }^{66}$ Para Fichte, o Nós ético ideal não é um Nós socialmente constituído, construído interpessoalmente, mas o Nós absoluto ou o Absoluto considerado como Nós. Remetendo à concepção, já no jovem Fichte encontrável, de uma identidade tão originária quanto definitiva de todos no puro $\mathrm{Eu},{ }^{67} \mathrm{e}$ apontando para a concepção, defendida pelo Fichte tardio, de um "Eu-comum" (Gesamtich) como fundamento de toda diferenciação individual, ${ }^{68} \mathrm{o}$ Eu deve ser visto, em Fichte, já que se trata primariamente de um Nós integral e

${ }^{64}$ GA I, 5, 227 (SdS).

${ }^{65}$ Quanto ao retorno de Fichte à expressão "massa" para caracterizar a origem pré-individual da individualidade na passagem da determinabilidade da indeterminação à determinidade através da (auto)determinação, cf. GA IV, 2, 240-1, 248 (WLnmH).

${ }^{66} \mathrm{Na}$ doutrina fichtiana do $\mathrm{Eu}$, corresponde à distinção entre massa racional (Vernunftmasse) e indivíduo racional (ou capaz de racionalidade) a diferença entre o "Eu absoluto" ou "puro" e o Eu individual. Quanto a isso, cf. GA IV, 2, 240-1 (WLnmH) e GA I, 4, 257 (VNDWL, 2. Einl.). Considerada em seu conjunto, a doutrina fichtiana do Eu prevê três passos histórico-filosóficos, indo da ipseidade pré-individual (Eu absoluto), passando pela pluralidade jurídica e eticamente normatizada de Eus (Eu como indivíduo) e chegando ao Eu-comum pósindividual, inatingível, mas incondicionalmente perseguível (ideia do Eu).

${ }^{67}$ Quanto a isso, veja-se a concepção antropologicamente articulada da racionalidade pura como unidade cognitiva, volitiva e emotiva do ser humano consigo mesmo, presente nas preleções de Jena sobre a determinação do erudito, do ano de 1794 (GA I, 3, 30-1).

${ }^{68}$ Quanto a isso, cf. Fichte. Werke IX, 559 (Die Thatsachen der Bewusstseins [1813]). não de um Nós plural, como uma reconfiguração, em roupagem social (ou protossocial), daquele Eu pré-individual absoluto em que começou a trajetória especulativa de Fichte desde o Eu até o Mim, do Eu ao Tu, do Mim ao Ti e do Ti ao Mim, e ao qual, após a viagem pelo mundo, ela deve enfim conduzir de volta.

Recebido para publicação em 13 outubro de 2012 Aceito em 04 de novembro de 2012

\section{REFERÊNCIAS}

BREAZEALE, D. Die Systematischen Funktionen Des Praktischen Bei Fichte Und Desses Systematische Vieldeutigkeit”. In: MANZ, H. G.; ZÖLLER, G. Fichtes praktische Philosophie. Eine systematische Einführung. Olms: Hildesheim/Zurich, 2006. p.39-72.

BUBNER, R. Von der Aufforderung zur Anerkennung. In: STOLZENBERG, J. (Org.) Subjektivität und Metaphysik. Konrad Cramer Zu Ehren Aus Anlass seines 65. Geburtstages: Göttingen, 2001. p.610-669.

CLAESGES, U. Geschichte des Selbstbewusstseins. Der ursprung des Spekulatives Problems in Fichtes Wissenschaftslehre von 1794-95. Den Haag, 1974.

FRANKS, P. Freedom, Tatsache and Tathandlung in the development of fichte's Jena Wissenschaftslehre. Archiv für Geschichte der Philosophie, n.79, p.310-323,1997.

HONNETH, A. Kampf um Anerkennung. Zur Moralischen Grammatik Sozialer Konflikte. Frankfurt/Main: Suhrkamp, 2003;

Verdinglichung. Eine Anerkennungstheoretische Studie. Frankfurt/Main: Suhrkamp, 2005.

JACOBI, Friedrich H. Werke. 6 Bde. Leipzig, 1812-1815, Bd II, 1, p.211.

LICHTENBERG, G.C. Schriften und Briefe. In: PROMIES, W. (Org.) 4 Bände und ein Kommentarband. Munique: 1967-1974, Bd 2, p.412 (K 76)

PHILONENKO, A. La liberté humaine dans la philosophie de Fichte. Paris: Vrin, 1966.

RICOEUR, P. Wege der Anerkennung. Erkennen, Wiedererkennen, Anerkanntsein. Frankfurt/Main: Suhrkamp, 2006.

SELLARS, W. [...] este Eu ou ele ou isto (a coisa) que pensa [...]. Proceedings and Addresses of the American Philosophical Association, n.44 p.5-31, 1970-1971.

STOLZENBERG, J. Fichtes Begriff der Intellektuellen Anschauung. Die Entwicklung in den Wissenschaften von 1793/94 bis 1801/02. Stuttgart: 1986.

THEUNISSEN, M. Der Andere.Studien zur Sozialontologie der Gegenwart. Berlim: The Gruyter, 1965.

WALDENFELS, B. Grundmotive einer Phänomenologie des Fremden. Frankfurt/Main: Suhrkamp, 2006.

WILLIAMS, R. Recognition: Fichte and Hegel on the Other. Albany: State University of New York, 1992. 
Hegel's Ethics of Recognition. Berkeley: University of California Press, 1998.

ZÖLLER, G. Lichtenberg and Kant on the subject of thinking. Journal of the History of Philosophy, v.30, issue 3, p.417-441,1992.

An eye for an I: fichte's transcendental experiment. In: KLEMM, D.; ZÖLLER, G. Figuring the self: subject, individual, and others in classical German Philosophy. Albany: State University of New York, 1997. p.73-95.

Fichte's transcendental philosophy: the original duplicity of intelligence and will. Cambridge: Cambridge U.P, 1998a. p.11-24, 43-54.

ZÖLLER, G. Das Element aller Gewissheit': Jacobi, Kant und Fichte über den Glauben. Fichte-Studien, [S.1.], n.14, p.21-41, 1998. Esp. 23 e ss.

Die Bestimmung der Bestimmung des Menschen bei Mendelssohn und Kant. In: GERHARDT, V. et al. (Org.) Kant und die Berliner Aufklärung. Akten des 9 Internationalen Kant-Kongresses. Berlim; Nova York 2001. v.4, p.476-489.
Konkrete Ethik. Universalität und Partikularität in Fichtes System der Sittenlehre. In: ENGELHARD, K. HEIDEMANN, D. (Org.) Ethikbegründungen Zwischen Universalismus und Relativismus. Berlim; Nova York, 2005. p.203-229.

. G. Fichte's Foundation of Natural Right And The Mind-Body Problem. In: BREAZEALE, D.; ROCKMORE, T. (Org.) Rights, Bodies, and Recognition. New essays on Fichte's Foundations of Natural Right. Aldershot: Burlington, 2006. p.90-106.

Leib, Materie und gemeinsames Wollen als Anwendungsbedingungen des Rechts. In: MERLE, I. (Org.) Fichtes Grundlage des Naturrechts. Berlim: Akademie Verlag, 2011. p.97-111. 


\section{THE SECOND PERSON - Fichte's Systematic Contribution}

\section{Günter Zöller}

The paper examines, systematically, the way in which Gottlieb Fichte presents the second person, heeding not to isolate such exposition, which, in fact, can only be understood in the full context of Fichte's works. In the recomposition of the rigorous movement of figures such as the 'I', the 'Me', the 'You' and the 'Us', the goal is to show how the I should finally be regarded in Fichte, since it is primarily question of an integral Us and not a plural Us, as a reconfiguration, in a social (or proto-social) clothing, of that absolute pre-individual I from whence Fichte's speculative journey from the I to the Me, from the I to the You, from the Me to the You (oblique), and from the You (oblique) to the Me, started, and to which, after travelling the world, it must eventually lead back.

KEY-WORDS: Fichte. First person. Second person. Intersubjectivity.

\section{LA DEUXIEME PERSONNE - La contribution systématique de Fichte}

\section{Günter Zöller}

Le texte se penche systématiquement sur la manière dont Gotlieb Fichte présente la deuxième personne, en ayant soin de ne pas isoler cette exposition qui, de fait, ne peut être comprise que dans le contexte global de l'œuvre. Lors de la recomposition du mouvement rigoureux de figures telles que le 'Je', le 'Moi', le 'Tu' et le 'Nous', nous avons l'intention de montrer comment le Je doit enfin être perçu chez Fichte puisqu'il s'agit premièrement d'un Nous faisant partie intégrante et non pas d'un Nous pluriel, comme une reconfiguration, revêtu d'un aspect social (ou protosocial), du fameux Je pré-individuel absolu par lequel a commencé la trajectoire spéculative de Fichte depuis le Je jusqu'au Moi, du Je au Tu, du Moi au Toi et du Toi au Moi et qui, après avoir parcouru le monde, doit enfin revenir au point de départ.

Mots-CLÉs: Fichte. Première Personne. Deuxième Personne. Intersubjectivité.

Günter Zöller - Doutor em Filosofia. Professor de Filosofia da Universidade de Munique. Realizou pesquisas nas universidades de Brown, Harvard, Tübingen, Oxford (Queen's College) e na École Normale Supérieure (Paris). Foi professor visitante nas universidades de Princiton, Emory, Nacional de Seul e Internacional de Veneza, e atualmente na Universidade McGill (Canadá). Membro da Comissão Kant da Academia de Ciências de Berlim-Brandenburgo, e editor-chefe das Obras de J. G. Fichte da Academia de Ciências da Bavária. Publicou trabalhos dedicados a diversos autores, entre os quais Kant (em particular a sua teoria da subjetividade), Schopenhauer, Heidegger, Brentano, Schelling, Husserl, Sartre e Fichte, tendo à filosofia transcendental deste último consagrado um estudo sistemático. Publicações recentes: A música como vontade e representação, a sair na revista Kritikon; "A atividade propriamente metafísica do homem”. Nietzsche acerca da justificação estética da existência do mundo, a sair na revista Analytika. 
